\title{
Dietary approach to hypertension based on low glycaemic index and principles of DASH (Dietary Approaches to Stop Hypertension): a randomised trial in a primary care service
}

\author{
Sílvia Tereza Rodrigues Moreira Lima ${ }^{1 *}$, Bárbara da Silva Nalin de Souza ${ }^{2}$, \\ Ana Karina Teixeira França ${ }^{1}$, Natalino Salgado Filho ${ }^{3}$ and Rosely Sichieri ${ }^{2}$ \\ ${ }^{1}$ Department of Health Sciences, Federal University of Maranhão, Avenida dos Portugueses, $s / n$, \\ Cidade Universitária (Bacanga), São Luís, MA, Brazil \\ ${ }^{2}$ Institute of Social Medicine, State University of Rio de Janeiro, Rua São Francisco Xavier, \\ 524 Bloco E, sala 7002, Rio de Janeiro, RJ, Brazil \\ ${ }^{3}$ Department of Medicine I, Federal University of Maranhão, Praça Gonçalves Dias $n^{\circ} 2$, \\ Centro, São Luís, MA, Brazil \\ (Submitted 20 July 2012 - Final revision received 3 January 2013 - Accepted 6 February 2013 - First published online 30 April 2013)
}

\begin{abstract}
Hypertension is one of the leading causes of morbidity and mortality in Brazil. Diet may play an important role in reducing blood pressure (BP), as has been shown for diets high in fruits, vegetables and low-fat dairy products and low in salt (Dietary Approaches to Stop Hypertension (DASH)-Na). A low-glycaemic index Brazilian diet combined with the principles of the DASH-Na diet was evaluated in a randomised study of 206 individuals who were followed for 6 months. In the control group (CG), counselling was based on standard care and mainly focused on salt intake reduction. An intention-to-treat analysis showed that, after 6 months, systolic BP was reduced by $14.4 \mathrm{mmHg}$ and diastolic BP by $9.7 \mathrm{mmHg}$ in the experimental group (EG), compared with 6.7 and $4.6 \mathrm{mmHg}$, respectively, in the CG. After adjusting for body weight, $\mathrm{BP}$ at baseline and age, these changes were 12.1 and $7.9 \mathrm{mmHg}$, respectively. Urinary Na excretion was also reduced by $43.4 \mathrm{mEq} / 24 \mathrm{~h}$ in the EG. Food intake was modified accordingly during the intervention with an increase in the consumption of vegetables (2.97-5.85 frequency of consumption measured in three non-consecutive days), fruits (4.09-7.18), beans $(1.94-3.13)$ and fish $(1.80-2 \cdot 74)$ by the EG. The present study showed the feasibility of a Brazilian dietary approach to treating hypertension by reducing urinary $\mathrm{Na}$ excretion and $\mathrm{BP}$, changes that may have a great impact on public health and promote the benefits of controlling hypertension.
\end{abstract}

Key words: Food consumption: Hypertension: Dietary Approaches to Stop Hypertension: Urinary sodium excretion

Arterial hypertension is one of the most important modifiable ${ }^{(1)}$ and well-established risk factors for $\mathrm{CVD}^{(2)}$ and neurocognitive dysfunction $^{(3)}$. In Brazil, the prevalence of hypertension reaches $23.3 \%$ in the adult population ${ }^{(4)}$ and, despite the actions of prevention and control implemented by the Ministry of Health ${ }^{(5)}$, for this morbidity, less than one-third of individuals diagnosed with hypertension are able to lower their blood pressure (BP) levels adequately with the recommended treatment ${ }^{(6)}$.

Trends in the Brazilian dietary pattern are consistent with the increasing prevalence of chronic disease ${ }^{(7)}$ and are mainly characterised by a low intake of milk, fruits and vegetables ${ }^{(8)}$. The Dietary Approaches to Stop Hypertension (DASH) diet has been shown to be an effective non-pharmacological treatment for the control of hypertension ${ }^{(6)}$ and emphasises the increased consumption of fruits, vegetables and low-fat dairy products, as well as reduced salt intake (DASH-Na) ${ }^{(9)}$. Diets with a low glycaemic index (GI) are also potentially effective in reducing BP, as indicated in a large randomised study ${ }^{(10)}$.

Systematic reviews of the role of salt-reduced diets and weightloss diets have shown small, long-term effects on BP. However, it would be problematic to make generalisations about the effect of the DASH diet for many different populations ${ }^{(11,12)}$.

In the present study, we combined the principles of the DASH-Na diet with the ingestion of low-GI foods that are highly consumed in Brazil to design a diet that could be affordable, sustainable and culturally acceptable. Thus, the aim of the present study was to evaluate the impact of a Brazilian dietary approach to hypertension on BP levels and

Abbreviations: BP, blood pressure; CG, control group; DASH, Dietary Approaches to Stop Hypertension; DBP, diastolic blood pressure; EG, experimental group; GI, glycaemic index; SBP, systolic blood pressure.

*Corresponding author: S. T. R. M. Lima, fax +559832 359334, email silviaterezam@gmail.com 
urinary $\mathrm{Na}$ and $\mathrm{K}$ excretion in hypertensive patients who were being monitored by primary health care providers in a poor region of Brazil.

\section{Methods}

The randomised trial was conducted in two primary care health units that assist hypertensive patients (Program HiperDia of the Brazilian Ministry of Health). The units were situated in the urban area of the city of São Luís, Maranhão, Brazil.

\section{Participants}

Participants who were at least 20 years of age were recruited between January 2010 and September 2011 from the list of participants in the Program HiperDia, a programme dedicated to the treatment of hypertensive patients located in the city of São Luís, Maranhão, Brazil. Patients with diabetes, chronic renal diseases and cancer, as well as pregnant women, were excluded from the study. Of the 673 total eligible patients, 206 individuals were randomised into either the control group (CG) or the experimental group (EG). The patient randomisation list was computer-generated by blocking. Sealed envelopes were used at the clinic to randomise the patients. The progress of the patients during the study is shown in Fig. 1. Assuming a reduction in systolic BP (SBP) of $7 \cdot 1 \mathrm{mmHg}$ and a standard deviation of $10 \mathrm{mmHg}^{(9)}$, with a significance level of $5 \%$ and $80 \%$ power, a sample size of thirtyone subjects per arm (total $n$ 62) was required.

A diagnosis of hypertension, as proposed by the Ministry of Health of Brazil and adopted by the HiperDia Program, was made for individuals with a SBP $\geq 140 \mathrm{mmHg}$ and/or diastolic $\mathrm{BP}$ (DBP) $\geq 90 \mathrm{mmHg}^{(1)}$ who are not using antihypertensive medication $^{(5)}$. The present study was conducted according to the guidelines laid down in the Declaration of Helsinki, and all procedures involving human subjects/patients were approved by the Ethics Committee of the University Hospital of Federal University of Maranhão (protocol no. 312/09) and the trial was registered at the Brazilian Register Clinical Trials of the Ministry of Health of Brazil (no. RBR8ztcv9). Written informed consent was obtained from all subjects/patients.

Intervention. Both groups (EG and CG) received standard care focused on salt intake reduction and hypertension control. The EG, in addition to standard care, also received monthly nutritional counselling provided by a nutritionist, which was based on the principles of the $\mathrm{DASH}^{(13)}$ and the glycaemic levels of common foods $^{(14)}$. These recommendations were focused on foods with a low to moderate GI (GI < 70), with glucose as the reference standard and using the foods listed in the 'International Tables of Glycemic Index and Glycemic Load Values, ${ }^{\text {(15). }}$

Compared with regular diets, the one proposed in the present study encouraged increased intake of fruits, vegetables, low-fat dairy products, beans and manioc products, while discouraging excess consumption of salt, meats and meat products and sugarsweetened beverages. Food item choices were also adapted to the local production and eating habits (Fig. 2).

The CG received standard care focused on reducing $\mathrm{Na}$ intake, according to assistance provided by the health unit. At the end of the study, an adapted Brazilian diet was also recommended for implementation by the CG.

\section{Data collection}

Subjects answered a questionnaire on sociodemographic data, co-morbidities and lifestyle factors. Physical activity level was measured by a validated questionnaire that included leisure, occupational, commuting and housework activities ${ }^{(16)}$.

Weight was measured using an electronic digital scale (Líder ${ }^{\circledR}$ ), and height was measured using a portable stadiometer (Alturexata ${ }^{\circledR}$ ). BMI was calculated as weight in $\mathrm{kg}$ divided by the square of height in $\mathrm{m}\left(\mathrm{kg} / \mathrm{m}^{2}\right)$. BMI were classified according to the WHO standards, which are defined as follows: $<25 \cdot 0 \mathrm{~kg} / \mathrm{m}^{2} ; 25 \cdot 0-29 \cdot 9 \mathrm{~kg} / \mathrm{m}^{2} ; \geq 30 \cdot 0 \mathrm{~kg} / \mathrm{m}^{2(17)}$.

Dietary intake was estimated by three non-consecutive $24 \mathrm{~h}$ records, including two weekdays and one weekend day, in

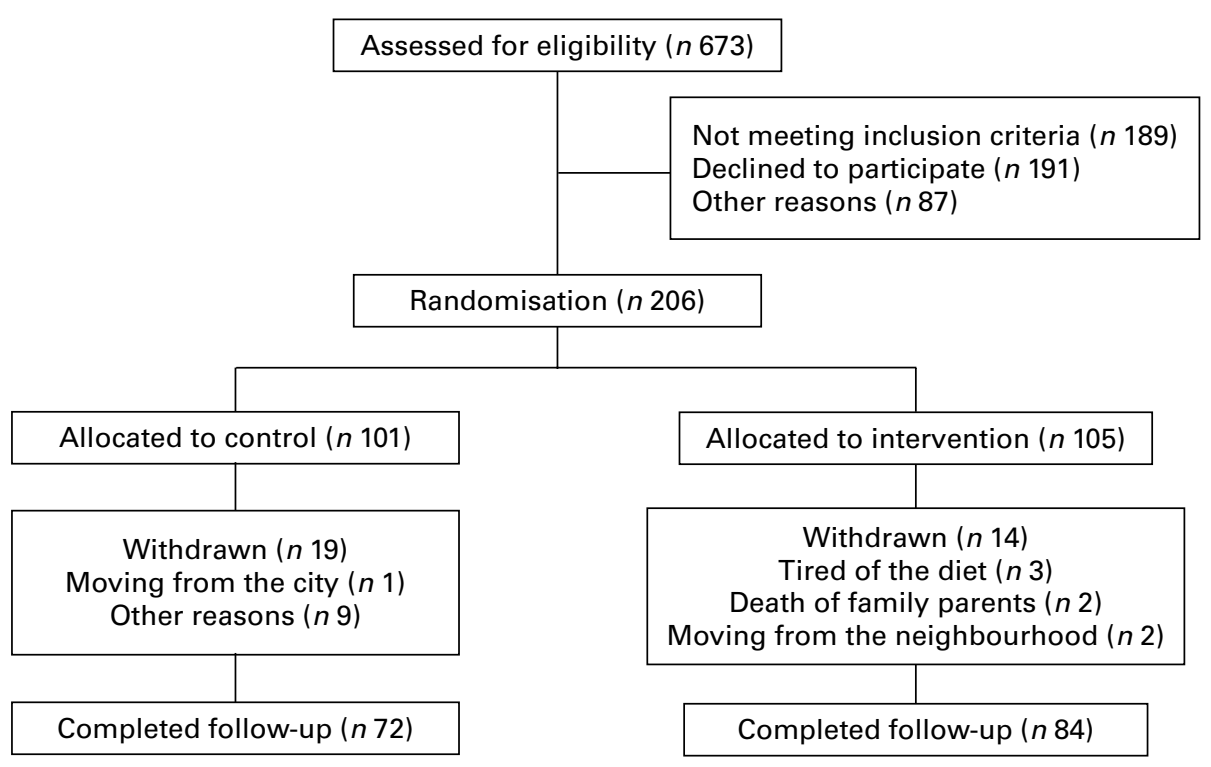

Fig. 1. Progress of the participants during the study. 
- Breakfast and snacks

Milk products: skimmed milk, creamed curd, white low-fat cheese and low-fat yogurt

Bread: whole bread, French bread, oat (oat bran), maize or rice, couscous maize or preparation of maize, cassava, whole or water cracker

Fruits : avocado, pineapple, acerola, count fruit, banana, hog-plum, cashew, star fruit, guava, jackfruit, orange, lemon, apple, mango, papaya, passion fruit, watermelon, melon, pear, pitomba, sapodilla, tangerine, grape

- Lunch and dinner

Cereals (every day): parboiled/coarse rice, rice with vinegar or other greens and pasta

Beans (every day): bean and soya

Green vegetables: cabbage leaf, lettuce and vinegar

Others vegetables: carrots, cabbage, cassava, cucumber, eggplant, gherkin, onion, okra, pepper, pumpkin, tomato, sweet potato/potatoes and pod

Meats, eggs and fish: lean meat, beef liver, bovine viscera, eggs (egg white), fishes, skinless chicken, sardine fish, tuna fish, shrimp and mussels

Desserts: fruits, jelly fruit and jam

Soups: vegetables and beans without rice or pasta

- Oils: olive oil and soyabean oil

- Spices: garlic, bay leaf, chive, coriander, oregano, parsley leaf and pepper

Fig. 2. Food groups included in the basic menu.

which all foods and beverages consumed, their time of consumption, the quantity consumed (in units of household measurements), the form of food preparation and the location of preparation were recorded. For more detailed information, a form with instructions about how to report food consumption was provided to the participants.

Nutritional analysis was performed using BRASIL-NUTRI ${ }^{\circledR}$ software, which was developed by Instituto Brasileiro de Geografia e Estatística and has been utilised by national surveys $^{(18)}$.

BP was measured using an electronic sphygmomanometer (HEM-742INT; Omron ${ }^{\circledR}$ ), in accordance with the procedures recommended by the American Heart Association ${ }^{(19)}$. Overall, three measurements were taken, and the mean was calculated.

A $24 \mathrm{~h}$ urinary $\mathrm{Na}$ and $\mathrm{K}$ excretion test was performed. Patients received appropriate bottles and were carefully instructed to collect all urine produced during the $24 \mathrm{~h}$ period, to continue drinking water normally throughout the day and to discard the first urine in the morning of the initial collection day ${ }^{(20)}$. Urinary $\mathrm{Na}$ excretion was measured spectrophotometrically and converted to $\mathrm{mEq} / \mathrm{l}$. Na intake was estimated by assuming that approximately $86 \%$ of the total $\mathrm{Na}$ intake of the day is excreted in the urine ${ }^{(21)}$.

\section{Nutritional counselling}

During the 6-month follow-up study, BP and anthropometric measures were recorded monthly, and food consumption evaluation took place both in the third month and at the end of the study. On the evening of the day before the appointment, patients were contacted to either confirm their clinical appointment or reschedule it.

The EG received a diet plan with a food equivalency list and schedules in which food groups and servings were distributed according to and between the main meals. This plan was reinforced in each visit beginning with the first appointment. The foods included in dietary recommendations were based on the DASH diet ${ }^{(13)}$, with the reduction of salt intake and the inclusion of low-GI food items ${ }^{(14)}$. Thus, increased consumption of fruits, vegetables, fish, whole grains, parboiled rice, beans and natural spices (such as pepper, garlic, chives, green scent and oregano) was emphasised to reduce Na intake. The diet was therefore also high in $\mathrm{K}, \mathrm{Mg}$ and fibre, as well as being lower in saturated fat, total fat, cholesterol, refined grains, $\mathrm{Na}$ and sweets. Encouraged foods are outlined in Fig. 2.

The recommendations included daily consumption of the following: three servings of low-fat milk; three to five servings of fruits; four to five servings of vegetables; one serving of legumes; five to nine servings of grains, roots and tubers; one to two servings of meat, mainly fish. Additionally, all food consumption was to be distributed over five to six meals a day ${ }^{(22)}$.

In the follow-up appointments, the diet plan was adjusted and nutrition education was discussed. Conversations focused on patient difficulties and the importance of healthy eating habits. At the end of the study, the groups underwent a new $24 \mathrm{~h}$ urine collection. 


\section{Analysis}

Age was categorised into $<60$ and $\geq 60$ years. The family monthly income was also categorised into multiples of minimum wage (which in Brazil was approximately \$US 283.00): $\leq 2$; 3-5; $\geq 6$. Participants were classified as white or nonwhite according to their skin colour. Educational level was assessed in years of schooling: $<4 ; 4-8$; $\geq 8$. Participants were classified as smokers or non-smokers, as well as alcohol consumers or non-alcohol consumers. Patients were considered physically active if they performed at least $150 \mathrm{~min}$ of weekly physical activity.

All statistical analyses were performed using SAS software (version 9.1; SAS Institute, Inc.). Initially, raw data were tested for normality using the Shapiro-Wilk test. The baseline characteristics of the two groups were compared using Student's $t$ test if the variables were continuous or Fisher's exact test if the data were categorical. A paired $t$ test was used to compare changes in urinary $\mathrm{Na}$ and $\mathrm{K}$ excretion from baseline to post-intervention. Repeated-measures regression analyses were performed for measurements of BP and weight using mixed models. Data were adjusted for baseline values of BP and weight, weight change, age and duration of intervention. Results were considered as statistically significant at a one-tailed level of 0.05.

\section{Results}

Of the 206 individuals randomised in the study, 156 completed the data collection (Fig. 1). The baseline characteristics of the participants in the two groups are shown in Table 1 . No sig-

Table 1. Baseline characteristics of the participants according to intervention

\begin{tabular}{|c|c|c|c|}
\hline Characteristics & $\begin{array}{c}\text { Experimental } \\
\text { group }(n 105)(\%)\end{array}$ & $\begin{array}{c}\text { Control group } \\
(n 101)(\%)\end{array}$ & $\begin{array}{c}P \\
\left(\chi^{2} \text { test }\right)\end{array}$ \\
\hline \multicolumn{4}{|l|}{$\operatorname{Sex}(\%)$} \\
\hline Female & 81.9 & 73.3 & 0.14 \\
\hline \multicolumn{4}{|l|}{ Age (years) } \\
\hline$<60$ & $55 \cdot 2$ & $41 \cdot 6$ & 0.05 \\
\hline$\geq 60$ & $44 \cdot 8$ & 58.4 & \\
\hline \multicolumn{4}{|l|}{ Skin colour (\%) } \\
\hline Non-white & $86 \cdot 7$ & $87 \cdot 1$ & 0.92 \\
\hline \multicolumn{4}{|l|}{$\begin{array}{l}\text { Income (minimum } \\
\text { wage) }\end{array}$} \\
\hline$\leq 2$ & $36 \cdot 2$ & $28 \cdot 7$ & 0.30 \\
\hline $3-5$ & 53.3 & 54.5 & \\
\hline$\geq 6$ & $10 \cdot 5$ & $16 \cdot 8$ & \\
\hline \multicolumn{4}{|l|}{ Schooling (years) } \\
\hline$<4$ & $27 \cdot 6$ & 31.7 & 0.81 \\
\hline $4-8$ & 49.5 & $46 \cdot 5$ & \\
\hline$\geq 8$ & $22 \cdot 9$ & 21.8 & \\
\hline \multicolumn{4}{|c|}{ Current smoking (\%) } \\
\hline Yes & $5 \cdot 7$ & 3.0 & 0.33 \\
\hline \multicolumn{4}{|l|}{ Current drinking (\%) } \\
\hline Yes & 23.8 & $15 \cdot 8$ & 0.15 \\
\hline \multicolumn{4}{|l|}{$\begin{array}{l}\text { Physical activity } \\
\text { leisure (\%) }\end{array}$} \\
\hline Active & $24 \cdot 8$ & $23 \cdot 8$ & 0.87 \\
\hline \multicolumn{4}{|l|}{ BMI $\left(\mathrm{kg} / \mathrm{m}^{2}\right)$} \\
\hline$<25.0$ & $28 \cdot 6$ & 33.7 & 0.78 \\
\hline $25 \cdot 0-29 \cdot 9$ & $38 \cdot 1$ & 38.6 & \\
\hline$\geq 30.0$ & 33.3 & $27 \cdot 7$ & \\
\hline
\end{tabular}

nificant differences in any of the characteristics were observed between the groups, except for age.

All patients received essential drugs for hypertension treatment monthly. Antihypertensive medications provided by the Ministry of Health and taken by the subjects consisted of angiotensin-converting enzyme inhibitors, $\beta$-blockers and the diuretic hydrochlorothiazide. A total of one, two or three antihypertensive agents were used by 64,33 and $3 \%$ of the subjects, respectively.

Fig. 3 shows BP changes observed during the follow-up. Patients who underwent the dietary intervention had a statistically significant reduction in both SBP and DBP in comparison with CG patients ( $P=0 \cdot 02, P=0 \cdot 04$, respectively). The mean of both SBP and DBP decreased by 14.4 and $9.7 \mathrm{mmHg}$, respectively, in the EG, compared with 6.7 and $4.6 \mathrm{mmHg}$ in the CG.

After adjusting for baseline values of BP and weight, age and duration of intervention, there was a $7.9 \mathrm{mmHg}$ DBP and a $1.7 \mathrm{~kg}$ weight reduction in the EG. For both analyses, the variable time $\times$ intervention, which tests changes over time related to the intervention, was statistically significant (Table 2).

Table 3 reports the $24 \mathrm{~h}$ urinary $\mathrm{Na}$ and $\mathrm{K}$ excretion in all patients. At baseline, the mean urinary $\mathrm{Na}$ in the EG was $151 \mathrm{mEq} / 24 \mathrm{~h}$. At the 5-month follow-up, the mean urinary $\mathrm{Na}$ dropped to $106 \mathrm{mEq} / 24 \mathrm{~h}$. This $43.4(95 \%$ CI 99,114$) \mathrm{mEq} / 24 \mathrm{~h}$ reduction was statistically significant $(P<0 \cdot 01)$. In the CG, urinary $\mathrm{Na}$ increased by $2.5 \mathrm{mEq} / 24 \mathrm{~h}$, which was not significantly different $(P=0.77)$. The $24 \mathrm{~h}$ urinary $\mathrm{K}$ increased by $3.4 \mathrm{mEq} /$ $24 \mathrm{~h}$ for the EG and decreased by $4.1 \mathrm{mEq} / 24 \mathrm{~h}$ in the CG, but the changes were not statistically significant $(P=0.13$ and $P=0 \cdot 07)$.

Food intake at baseline and follow-up (first-wave follow-up) and at the last month of the follow-up (second-wave follow-up) are shown in Table 4. In the EG, a gradual increased intake of the encouraged foods that the patients were counselled to eat was observed throughout the intervention period.

Changes over time in dietary intake were associated with a greater and statistically significant change in the GL of the intervention group compared with the CG. A 9.6 reduction in the intervention group compared with the CG was observed, but this change was mostly related to a reduction in carbohydrate intake with almost no change in the GL. A statistically significant reduction in lipids in the intervention compared with the CG was also observed (Table 5).

\section{Discussion}

The present study showed that individuals diagnosed with hypertension who were being treated by a primary health care provider and who were advised to follow a low GI and $\mathrm{DASH}$ diet showed a reduction in both $\mathrm{BP}$ and urinary $\mathrm{Na}$ excretion.

The hypotensive effect of the experimental diet when compared with the control, based mainly on salt reduction, was $12 \cdot 1 \mathrm{mmHg}$ for SBP and $7.9 \mathrm{mmHg}$ for DBP, values that are of high clinical significance. The levelling effect on BP observed at 3 months was probably attributed to the initial expectations 


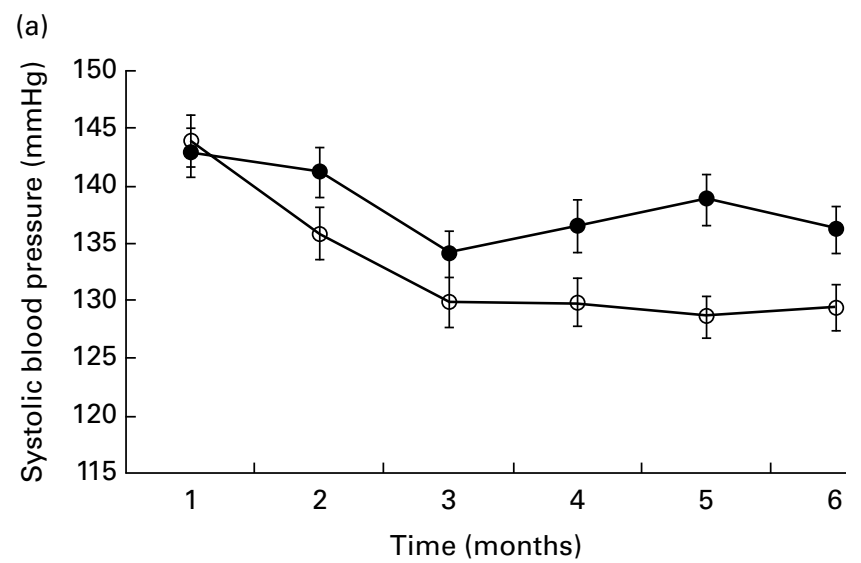

(b)

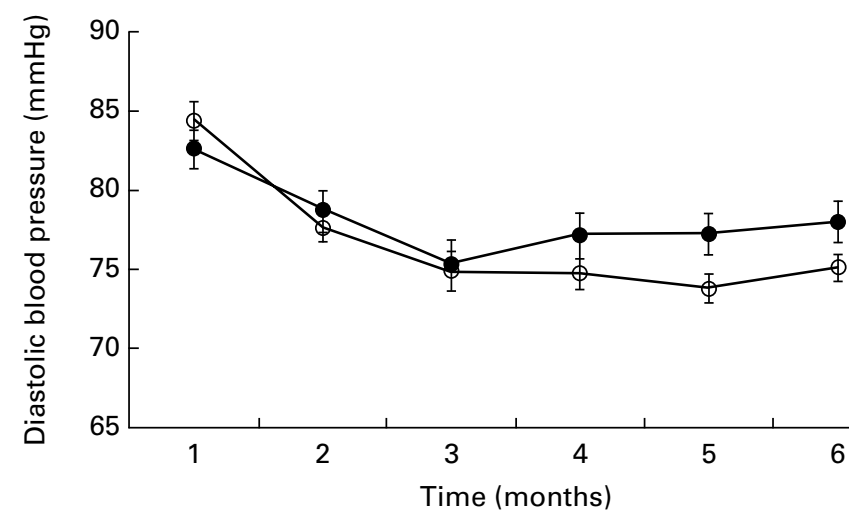

Fig. 3. (a) Systolic blood pressure and (b) diastolic blood pressure according to intervention. Values are means, with their standard errors represented by vertical bars. Mean values were significantly different for the experimental $(n 105, \ominus)$ and control $(n 101,-)$ groups $(P<0.05)$.

of the patient related to his/her participation in a study for hypertension treatment and the type of assistance provided, which led patients to achieve greater self-care and feel more assisted by the health team. However, this effect was not maintained until the end of the experiment; the nutritional intervention was received by the CG only after the completion of the study.

The reductions observed in the present study were greater than those observed in the studies of salt reduction alone. Meta-analyses of randomised controlled trials showed that the effects of reduced $\mathrm{Na}$ intake on $\mathrm{BP}$ in hypertensive patients are about half of those observed in the present study, but also showed a greater effect on SBP reduction. Thus, Horvath et $a l .{ }^{(12)}$ noted a significant reduction in SBP and DBP $(6.26$ and $3.41 \mathrm{mmHg}$, respectively). Similarly, Graudal et al. ${ }^{(23)}$ reported a reduction in SBP and DBP levels of by 3.5\%. However, another meta-analysis conducted by Taylor et al. ${ }^{(24)}$ showed modest SBP and DBP reductions that were not statistically significant.

The results of studies using only the DASH diet vary in the magnitude of its effect. The results of long follow-up studies such as the one in this study are much smaller than those observed in this study. The original DASH study ${ }^{(13)}$, conducted among 133 hypertensive patients, compared the effects of a traditional American diet with one enriched by fruits and vegetables. Notably, both diets contained $3000 \mathrm{mg} / \mathrm{d}$ of $\mathrm{Na}$. At an 8-week follow-up, an $11.4 \mathrm{mmHg}$ reduction in SBP and a $5.5 \mathrm{mmHg}$ reduction in DBP were observed. In a subsequent clinical trial, the effects of a traditional American diet and a DASH diet on BP levels were compared using three levels of $\mathrm{Na}$ intake. The lower Na content (1500 mg) DASH diet exhibited an $11.9 \mathrm{mmHg}$ SBP reduction when compared with a traditional American diet with a higher $\mathrm{Na}$ content $(3300 \mathrm{mg})^{(9)}$.

The multicentre PREMIER study (Trial of Lifestyle Interventions for Blood Pressure Control) tested several 6-month follow-up dietary interventions, including the DASH, as part of an intervention using general behaviour modification to reduce $\mathrm{BP}^{(25)}$. The $\mathrm{DASH}$ group exhibited a $14.2 \mathrm{mmHg}$ reduction in SBP and a $7.4 \mathrm{mmHg}$ in DBP, which were statistically significant. Similarly, Huggins et al. ${ }^{(26)}$ evaluated the effect of the DASH diet intervention in hypertensive patients in a 4-week follow-up study, and observed a $16.7 \mathrm{mmHg}$ reduction in SBP and a $10.3 \mathrm{mmHg}$ reduction in DBP. Modest but significant results have been reported by Hsieh et $a l{ }^{(27)}$, who achieved reductions in SBP $(5.9 \mathrm{mmHg})$ and DBP $(3.7 \mathrm{mmHg})$ in a 6-month follow-up study using a community nutritional education programme to decrease BP. On the other hand, a study conducted by Charlton et al. ${ }^{(28)}$ showed BP reduction after the first 4 weeks that was not observed throughout the entire follow-up period ( 8 weeks).

Compared with randomised studies ${ }^{(13,25,28)}$ and meta-analyses $^{(12,23)}$, combining salt reduction and dietary changes in a free-living population, in which dietary changes were based only on counselling, exhibited a significant reduction in BP. This indicates that the combination of DASH-Na with

Table 2. Blood pressure and weight changes during the follow-up according to intervention*

\begin{tabular}{|c|c|c|c|c|c|c|c|}
\hline & \multicolumn{6}{|c|}{ Follow-up (months) } & \multirow{2}{*}{$\begin{array}{c}\text { Time } \times \\
\text { intervention } \\
P\end{array}$} \\
\hline & 1 & 2 & 3 & 4 & 5 & 6 & \\
\hline Systolic (mmHg) & & & & & & & 0.08 \\
\hline Experimental & $143 \cdot 8$ & $141 \cdot 0$ & 137.4 & 135.5 & 133.5 & $131 \cdot 7$ & \\
\hline Control & $142 \cdot 9$ & $144 \cdot 0$ & $143 \cdot 3$ & 141.7 & $140 \cdot 9$ & $140 \cdot 0$ & \\
\hline Diastolic (mmHg) & & & & & & & $<0.01$ \\
\hline Experimental & $84 \cdot 6$ & $83 \cdot 1$ & $80 \cdot 6$ & $79 \cdot 2$ & $77 \cdot 9$ & $76 \cdot 7$ & \\
\hline Control & $82 \cdot 7$ & $82 \cdot 8$ & $82 \cdot 6$ & $81 \cdot 9$ & 81.5 & $81 \cdot 0$ & \\
\hline Weight (kg) & & & & & & & $<0.01$ \\
\hline Experimental & $65 \cdot 7$ & $65 \cdot 3$ & $65 \cdot 0$ & $64 \cdot 7$ & 64.3 & $64 \cdot 0$ & \\
\hline Control & 64.5 & 64.4 & $64 \cdot 4$ & $64 \cdot 4$ & $64 \cdot 4$ & $64 \cdot 3$ & \\
\hline
\end{tabular}

* The PROC MIXED model included weight, weight change, age, blood pressure at baseline, time and time $\times$ intervention (variable that measures changes over time). 
Table 3. Urinary sodium and potassium excretion of the participants according to intervention (Mean values and $95 \%$ confidence intervals)

\begin{tabular}{|c|c|c|c|c|c|c|c|c|}
\hline & \multicolumn{4}{|c|}{ Urinary excretion (mEq/24 h) } & \multicolumn{4}{|c|}{ Change from baseline $(\mathrm{mEq} / 24 \mathrm{~h})$} \\
\hline & \multicolumn{2}{|c|}{ Experimental group } & \multicolumn{2}{|c|}{ Control group } & \multicolumn{2}{|c|}{ Experimental group } & \multicolumn{2}{|c|}{ Control group } \\
\hline & Mean & $95 \% \mathrm{Cl}$ & Mean & $95 \% \mathrm{Cl}$ & Mean & $P^{*}$ & Mean & $P^{*}$ \\
\hline \multicolumn{9}{|l|}{ Baseline ( $n$ 206) } \\
\hline $\mathrm{Na}(\mathrm{mEq} / 24 \mathrm{~h})$ & $151 \cdot 0$ & $139.0,164.0$ & 134.0 & $121 \cdot 0,148 \cdot 0$ & & & & \\
\hline $\mathrm{K}(\mathrm{mEq} / 24 \mathrm{~h})$ & $42 \cdot 0$ & $39 \cdot 0,45 \cdot 0$ & 44.0 & $35 \cdot 0,54 \cdot 0$ & & & & \\
\hline \multicolumn{9}{|c|}{ Post-intervention ( $n$ 156) } \\
\hline $\mathrm{Na}(\mathrm{mEq} / 24 \mathrm{~h})$ & $106 \cdot 0$ & $99 \cdot 0,114 \cdot 0$ & $136 \cdot 0$ & $120 \cdot 0,152 \cdot 0$ & $-43 \cdot 4$ & $<0.01$ & 2.5 & 0.77 \\
\hline $\mathrm{K}(\mathrm{mEq} / 24 \mathrm{~h})$ & $45 \cdot 0$ & $42 \cdot 0,48 \cdot 0$ & $43 \cdot 0$ & $39 \cdot 0,48 \cdot 0$ & 3.4 & 0.13 & $-4 \cdot 1$ & 0.07 \\
\hline
\end{tabular}

${ }^{*} P$ calculated using a paired $t$ test of the change in urinary Na from baseline to post-intervention.

a low-GI diet is an effective approach to reduce hypertension in the clinical setting.

Changes in BP were also attributed to the weight reduction observed in the present study. While weight change did not explain the overall reduction in both SBP and DPB, as indicated in the analysis adjusted for BMI at baseline and the change in BMI, it was also a positive effect of dietary intervention. Weight change could not be easily maintained in longer follow-ups ${ }^{(9,14)}$, but the effect on BP was independent of weight change.

The results from randomised controlled trials examining the association between GI and CVD risk factors including BP and weight loss have not been consistent ${ }^{(29-32)}$. The PREMIER study examined these associations, but GI changes were not associated with changes in any risk factors at 6 months ${ }^{(33)}$. A low-GI diet is easy to follow in Brazil because beans and manioc are staple foods of very low glycaemic index ${ }^{(14)}$. The present results suggest a role for this approach combined with the DASH diet.

Recently, the Institute of Medicine Committee has recommended a level of $\mathrm{Na}$ intake no higher than $1500 \mathrm{mg} / \mathrm{d}$ $(65 \mathrm{mEq} / \mathrm{d})^{(34)}$. However, accomplishing this recommendation is not easy. A reasonable recommendation is the upper limit of $2300 \mathrm{mg} / \mathrm{d}(100 \mathrm{mEq} / \mathrm{d})$, which is similar to previous recommendations for the prevention and treatment of hypertension ${ }^{(6,35)}$.

In Brazil, $\mathrm{Na}$ intake is approximately $4500 \mathrm{mg} / \mathrm{d}$ and largely exceeds the maximum recommendation ${ }^{(36)}$. In the present study, EG patients achieved the minimum mean values of $106 \mathrm{mEq} / \mathrm{d}$ in urinary $\mathrm{Na}$ excretion after the dietary intervention, with a $43.4 \mathrm{mEq} / \mathrm{d}$ reduction that was statistically significant. Although this finding does not quite match the amount recommended by the Institute of Medicine Committee ${ }^{(34)}$, it is close to other reasonable recommendations ${ }^{(6,35)}$.

A Meta-Analysis of Healthful Diet Trials, Salt Reduction Counselling ${ }^{(37)}$ demonstrated a statistically significant decrease in urinary $\mathrm{Na}$ excretion. Another meta-analysis, conducted by Taylor et al. ${ }^{(24)}$, showed that a reduction in dietary salt intake was able to decrease urinary $\mathrm{Na}$ excretion by $39 \cdot 1 \mathrm{mEq} / 24 \mathrm{~h}$, although this result was not statistically significant.

In clinical trials, Nowson et al. ${ }^{(38)}$ and Huggins et al. ${ }^{(26)}$ observed a 43.1 and $36.1 \mathrm{mEq} / \mathrm{d}$ reduction in urinary $\mathrm{Na}$ excretion, respectively, after 4 weeks of the DASH diet intervention. However, the multicentre PREMIER study noted a $32.6 \mathrm{mEq} / \mathrm{d}$ reduction in urinary $\mathrm{Na}$ excretion of the DASH diet intervention group that did not reach statistical significance $^{(25)}$.

Minor reductions in urinary Na excretion were found in the original DASH study ${ }^{(13)}$, which showed a $10 \cdot 1 \mathrm{mEq} / \mathrm{d}_{\text {reduction }}$ with a diet enriched with fruits and vegetables and a $3.2 \mathrm{mEq} / \mathrm{d}$ reduction with the DASH diet. In another study, Robare et al. ${ }^{\text {(39) }}$ evaluated the effects of a DASH low-Na diet in 115 hypertensive patients in the USA using a 6-month follow-up study and observed a small decrease in urinary $\mathrm{Na}$ excretion $(6 \mathrm{mEq} / \mathrm{d})$. On the other hand, Charlton et al. ${ }^{(28)}$ noted a greater reduction

Table 4. Frequency of reported consumption in $3 d-$ records by food groups

\begin{tabular}{|c|c|c|c|c|}
\hline Food groups & Groups & Baseline & $\begin{array}{l}\text { First-wave } \\
\text { follow-up }\end{array}$ & $\begin{array}{l}\text { Second-wave } \\
\text { follow-up }\end{array}$ \\
\hline \multirow[t]{2}{*}{ Fruits } & Experimental & 4.09 & 4.44 & $7 \cdot 18$ \\
\hline & Control & 4.01 & 3.93 & 5.75 \\
\hline \multirow[t]{2}{*}{ Milk and dairy foods } & Experimental & $4 \cdot 74$ & $5 \cdot 30$ & $6 \cdot 36$ \\
\hline & Control & 4.75 & 5.09 & $6 \cdot 47$ \\
\hline \multirow{2}{*}{ Fish } & Experimental & 1.80 & 1.96 & $2 \cdot 74$ \\
\hline & Control & 1.95 & 1.75 & $2 \cdot 44$ \\
\hline \multirow[t]{2}{*}{ Beans } & Experimental & 1.94 & $2 \cdot 39$ & $3 \cdot 13$ \\
\hline & Control & $2 \cdot 27$ & 2.05 & $2 \cdot 63$ \\
\hline \multirow[t]{2}{*}{ Vegetables } & Experimental & 2.97 & 3.64 & $5 \cdot 85$ \\
\hline & Control & 2.98 & $2 \cdot 83$ & 3.57 \\
\hline \multirow[t]{2}{*}{ Added fats and oils } & Experimental & 2.50 & 2.94 & 2.98 \\
\hline & Control & 2.67 & $3 \cdot 24$ & 3.08 \\
\hline
\end{tabular}


Table 5. Energy and macronutrient intake, fibre and glycaemic index (Gl, glucose reference) and glycaemic load (GL) of the diet at baseline and follow-up comparing the experimental and control groups

\begin{tabular}{|c|c|c|c|c|c|c|c|c|}
\hline & \multicolumn{3}{|c|}{ Intervention } & \multicolumn{3}{|c|}{ Control } & \multirow[b]{2}{*}{$\begin{array}{c}\text { Change } \\
\text { over time* }\end{array}$} & \multirow[b]{2}{*}{$P \nmid$ (interaction) } \\
\hline & Baseline & $\begin{array}{l}\text { First-wave } \\
\text { follow-up }\end{array}$ & $\begin{array}{l}\text { Second-wave } \\
\text { follow-up }\end{array}$ & Baseline & $\begin{array}{l}\text { First-wave } \\
\text { follow-up }\end{array}$ & $\begin{array}{l}\text { Second-wave } \\
\text { follow-up }\end{array}$ & & \\
\hline Energy (kcal) & 1485 & 1466 & 1392 & 1485 & 1598 & 1621 & -105 & $<0.01$ \\
\hline Energy (kJ) & 6213 & 6133 & 5824 & 6213 & 6686 & 6782 & -105 & $<0.01$ \\
\hline Protein (g) & $78 \cdot 8$ & 83.0 & $87 \cdot 5$ & $76 \cdot 0$ & 83.4 & $88 \cdot 0$ & $3 \cdot 8$ & 0.69 \\
\hline Lipids (g) & $46 \cdot 0$ & $44 \cdot 0$ & $39 \cdot 0$ & $44 \cdot 1$ & $48 \cdot 3$ & $49 \cdot 3$ & $-6 \cdot 1$ & $<0.01$ \\
\hline Carbohydrates (g) & $18 \cdot 9$ & $18 \cdot 5$ & $17 \cdot 3$ & $19 \cdot 5$ & $20 \cdot 6$ & $20 \cdot 5$ & $-14 \cdot 7$ & $<0.01$ \\
\hline Fibre $(\mathrm{g})$ & $12 \cdot 4$ & $13 \cdot 5$ & $14 \cdot 0$ & $12 \cdot 9$ & $13 \cdot 3$ & $14 \cdot 2$ & 0.12 & 0.79 \\
\hline GI & 475 & 479 & 477 & 516 & 512 & 536 & -21 & 0.15 \\
\hline GL & 106 & 102 & 94 & 113 & 117 & 115 & -9.6 & $<0.01$ \\
\hline
\end{tabular}

* Change over time comparing the intervention with the control based on repeated measures with time and time $\times$ intervention variables.

$\dagger P$ value related to the change over time ( $P$ value of the variable time $\times$ intervention).

in urinary Na excretion $(14.6 \mathrm{mEq} / \mathrm{d})$ over a shorter follow-up period ( 8 weeks) after a low-Na diet intervention in hypertensive patients in South Africa.

The present findings on the reduction in urinary $\mathrm{Na}$ excretion are similar to those of randomised controlled trials ${ }^{(27,38)}$ and meta-analyses $^{(37)}$, again supporting the feasibility of dietary intervention in reducing $\mathrm{Na}$ in primary health care settings by tailoring changes in the diet to the habits of the population.

The current trend in Brazilian eating habits is characterised by a reduced consumption of fruits and vegetables ${ }^{(40)}$, which are good sources of $\mathrm{K}$, and the dietary intervention conducted in this study promoted an increased intake of all food groups for the EG. Although we observed an increase in food intake after the intervention, there was no significant difference in $\mathrm{K}$ excretion in the urine at $24 \mathrm{~h}$ after the intervention. One potential explanation for this finding may be the tendency for certain patients to overestimate their records of consumed foods considered beneficial to their treatment.

Furthermore, although our dietary counselling focused on changes in carbohydrate composition beyond changes in the lipid content of the diet, the most important changes observed were related to a lower load of carbohydrates in the EG, followed by a reduction in the fat content of the diet.

One positive aspect of the present study was that the monitoring of patients emphasised actively promoting compliance with keeping appointments and rescheduling missed appointments based on convenience and patient availability. Another positive point involves the methodology applied: a longitudinal 24-week follow-up study; analysis of $\mathrm{Na}$ and $\mathrm{K}$ intakes conducted by a $24 \mathrm{~h}$ urinary excretion test; detailed $24 \mathrm{~h}$ food records documented on three different occasions during the intervention. This method allowed for greater knowledge of the patients' eating habits, which may be reflected in the results. On the other hand, a limitation of the present study was that the hypertensive population was mainly composed of female and elderly patients at primary health care facilities.

In conclusion, dietary intervention to reduce BP tailored according to eating habits may have a major effect on $\mathrm{BP}$ reduction.

\section{Acknowledgements}

The authors declare that they have no actual or potential competing interests. The present study was funded by Fundação de Amparo e Pesquisa do Estado do Maranhão and Coordenação de Aperfeiçoamento de Pessoal de Nível Superior. N. S. F. and R. S. coordinated the research. S. T. R. M. L. and A. K. T. F. coordinated the data collection and conducted the dietary counselling. S. T. R. M. L., B. d. S. N. d. S., A. K. T. F. and R. S. conducted the data analyses and were involved in the writing of the manuscript. All the authors contributed to the redrafting, reading and approving of the final manuscript.

\section{References}

1. Sociedade Brasileira de Cardiologia, Sociedade Brasileira de Hipertensão, Sociedade Brasileira de Nefrologia (2010) VI Brazilian guidelines on hypertension. Arq Bras Cardiol 95 , $1-51$.

2. Oliveira-Martins S, Oliveira T, Gomes JJ, et al. (2011) Factors associated with arterial hypertension in pharmacy users in Portugal. Rev Saude Publica 45, 136-144.

3. Smith PJ, Blumenthal JA, Babyak MA, et al. (2010) Effects of the dietary approaches to stop hypertension diet, exercise, and caloric restriction on neurocognition in overweight adults with high blood pressure. Hypertension 55, 1331-1338.

4. Iser BP, Claro RM, de Moura EC, et al. (2011) Risk and protection factors for chronic non communicable diseases by telephone survey - VIGITEL-2009. Rev Bras Epidemiol 14, 90-102.

5. Brasil. Ministério da Saúde do Brasil. Secretaria de Atenção à Saúde. Departamento de Atenção Básica (2006) Hipertensão Arterial Sistêmica (Arterial Systemic Hypertension) no 65. Brasília: Ministério da Saúde.

6. Chobanian AV, Bakris GL, Black HR, et al. (2003) Seventh report of the Joint National Committee on Prevention, Detection, Evaluation, and Treatment of High Blood Pressure. Hypertension 42, 1206-1252.

7. Levy-Costa RB, Sichieri R, Pontes Ndos S, et al. (2005) Household food availability in Brazil: distribution and trends (1974-2003). Rev Saude Publica 39, 530-540.

8. Souza AM, Bezerra IN, Cunha DB, et al. (2011) Evaluation of food intake markers in the Brazilian surveillance system for chronic diseases - VIGITEL (2007-2009). Rev Bras Epidemiol 14, 44-52. 
9. Sacks FM, Svetkey LP, Vollmer WM, et al. (2001) Effects on blood pressure of reduced dietary sodium and the Dietary Approaches to Stop Hypertension (DASH) diet. $N$ Engl J Med 344, 3-10.

10. Gögebakan O, Kohl A, Osterhoff MA, et al. (2011) Effects of weight loss and long-term weight maintenance with diets varying in protein and glycemic index on cardiovascular risk factors: the diet, obesity, and genes (DiOGenes) study: a randomized, controlled trial. Circulation 124, 2829-2838.

11. Siebenhofer A, Jeitler K, Berghold A, et al. (2011) Long-term effects of weight-reducing diets in hypertensive patients. Cochrane Database of Systematic Reviews issue 9, CD008274.

12. Horvath K, Jeitler K, Siering U, et al. (2008) Long-term effects of weight-reducing interventions in hypertensive patients: systematic review and meta-analysis. Arch Intern Med 168, 571-580.

13. Appel LJ, Moore TJ, Obarzanek E, et al. (1997) A clinical trial of the effects of dietary patterns on blood pressure. DASH Collaborative Research Group. N Engl J Med 17, 1117-11124.

14. Sichieri R, Moura AS, Genelhu V, et al. (2007) An 18-mo randomized trial of a low-glycemic-index diet and weight change in Brazilian women. Am J Clin Nutr 86, 707-713.

15. Foster-Powell K, Holt SHA \& Brand-Miller JC (2002) International table of glycemic index and glycemic load values. Am J Clin Nutr 76, 55-56.

16. Matsudo S, Araújo T, Marsudo V, et al. (2001) Questionário Internacional de Atividade Física (IPAQ): estudo de validade e reprodutibilidade no Brasil (International Physical Activity Questionnaire (IPAQ): validity study and reproducibility in Brazil). Rev Bras Ativ Fis Saúde 6, 5-18.

17. World Health Organization (1995) Physical Status: The Use and Interpretation of Anthropometry. Report of a WHO Expert Committee. WHO Technical Report Series no. 854. Geneva: WHO.

18. Instituto Brasileiro de Geografia e Estatística (2011) Pesquisa de Orçamentos Familiares, 2008-2009. Análise do Consumo Alimentar Pessoal no Brasil (Household Budget Survey, 2008-2009. Analysis of Personal Food Consumption in Brazil). Rio de Janeiro: IBGE.

19. Pickering TG, Hall JE, Appel LJ, et al. (2005) Recommendations for blood pressure measurement in humans and experimental animals: part 1: blood pressure measurement in humans: a statement for professionals from the Subcommittee of Professional and Public Education of the American Heart Association Council on High Blood Pressure Research. Circulation 111, 697-716.

20. Ferreira-Sae MC, Gallani MC, Nadruz W, et al. (2009) Reliability and validity of a semi-quantitative FFQ for sodium intake in low-income and low-literacy Brazilian hypertensive subjects. Public Health Nutr 12, 2168-2173.

21. Holbrook JT, Patterson KY, Bodner JE, et al. (1984) Sodium and potassium intake and balance in adults consuming selfselected diets. Am J Clin Nutr 40, 786-793.

22. Philippi ST, Latterza AR, Cruz ATR, et al. (1999) Adapted food pyramid: a guide for a right food choice. Rev Nutr 12, 65-80.

23. Graudal NA, Hubeck-Graudal T \& Jürgens G (2012) Effects of low-sodium diet $v$ s. high-sodium diet on blood pressure, renin, aldosterone, catecholamines, cholesterol, and triglyceride (Cochrane Review). Am J Hypertens 25, 1-15.

24. Taylor RS, Ashton KE \& Moxham T (2011) Reduced dietary salt for the prevention of cardiovascular disease: a metaanalysis of randomized controlled trials (Cochrane review). Am J Hypertens 24, 843-853.

25. Appel LJ, Champagne CM, Harsha DW, et al. (2003) Effects of comprehensive lifestyle modification on blood pressure control: main results of the PREMIER clinical trial. JAMA 289, 2083-2093.

26. Huggins CE, Margerison C, Worsley A, et al. (2011) Influence of dietary modifications on the blood pressure response to antihypertensive medication. Br J Nutr 105, 248-255.

27. Hsieh YC, Hung CT, Lien LM, et al. (2009) A significant decrease in blood pressure through a family-based nutrition health education programme among community residents in Taiwan. Public Health Nutr 12, 570-577.

28. Charlton KE, Steyn K, Levitt NS, et al. (2008) A food-based dietary strategy lowers blood pressure in a low socio-economic setting: a randomised study in South Africa. Public Health Nutr 11, 1397-1406.

29. van Dam RM, Visscher AW, Feskens EJ, et al. (2000) Dietary glycemic index in relation to metabolic risk factors and incidence of coronary heart disease: the Zutphen Elderly Study. Eur J Clin Nutr 54, 726-731.

30. Frost GS, Brynes AE, Bovill-Taylor C, et al. (2004) A prospective randomized trial to determine the efficacy of a low glycaemic index diet given in addition to healthy eating and weight loss advice in patients with coronary heart disease. Eur J Clin Nutr 58, 121-127.

31. Ebbeling CB, Leidig MM, Sinclair KB, et al. (2005) Effects of an ad libitum low-glycemic load diet on cardiovascular disease risk factors in obese young adults. Am J Clin Nutr $\mathbf{8 1}$, 976-982.

32. Das SK, Gilhooly CH, Golden JK, et al. (2007) Long-term effects of 2 energy-restricted diets differing in glycemic load on dietary adherence, body composition, and metabolism in CALERIE: a 1-y randomized controlled trial. $\mathrm{Am} \mathrm{J}$ Clin Nutr 85, 1023-1030.

33. Lin PH, Chen C, Young DR, et al. (2012) Glycemic index and glycemic load are associated with some cardiovascular risk factors among the PREMIER study participants. Food Nutr Res 56, 1-8.

34. Institute of Medicine of the National Academies (2004) Dietary Reference Intakes for Water, Potassium, Sodium, Chloride, and Sulfate. Washington: National Academy of Sciences.

35. Whelton PK, He J, Appel LJ, et al. (2002) Primary prevention of hypertension: clinical and public health advisory from The National High Blood Pressure Education Program. JAMA 288, 1882-1888.

36. Sarno F, Claro RM, Levy RB, et al. (2009) Estimated sodium intake by the Brazilian population, 2002-2003. Rev Saude Publica 43, 219-225.

37. Lin JS, O'Connor E, Whitlock EP, et al. (2010) Behavioral counseling to promote physical activity and a healthful diet to prevent cardiovascular disease in adults: update of the evidence for the U.S. Preventive Services Task Force http://www.ncbi.nlm.nih.gov/books/NBK51030/ (accessed 11 May 2012).

38. Nowson CA, Worsley A, Margerison C, et al. (2004) Blood pressure response to dietary modifications in free-living individuals. J Nutr 134, 2322-2329.

39. Robare JF, Milas NC, Bayles CM, et al. (2010) The key to life nutrition program: results from a community-based dietary sodium reduction trial. Public Health Nutr 13, 606-614.

40. Brasil. Ministério da Saúde. Secretaria de Atsenção à Saúde. Coordenação-Geral da Política de Alimentação e Nutrição (2006) Guia alimentar para a população brasileira: promovendo a alimentação saudável (Food Guide for the Brazilian Population: Promoting Healthy Eating). Brasília: Ministério da Saúde. 